\title{
Addressing the Mental Health Problems of Chinese International College Students in the United States
}

\author{
Meirong Liu
}

\begin{abstract}
This article identifies unique mental health problems experienced by Chinese international students in the United States. The uniqueness of these problems suggests the need to address them independently from other Chinese and international student communities. First, an overview of the common sources of mental health problems and specific stressors these students face is provided. This article then develops culturally sensitive programming recommendations to improve collaborative efforts between health providers, mental health social workers, faculty, and academic staff within universities to serve these students more effectively.
\end{abstract}

Keywords: Chinese international student; mental health

\section{INTRODUCTION}

The increase in cultural diversity in the United States is reflected in its educational systems (Bradley, Parr, Lan, Bingi, \& Gould, 1995). Being an important center of information and advanced technology, along with its generous scholarship policy, the U.S. attracts more international students than any other country (Sandhu, 1995). During the 2004-2005 academic year, a total of 565,039 international students were studying at the academic institutions in the U.S. (Institute of International Education [IIE], 2006). Students from Asian countries represent more than half (55\%) of these students (IIE, 2006).

Transition to university can be a dramatic life change for all young people. First year university students can experience elevated psychological distress (Fisher \& Hood, 1987), and features of the new environment can interact with personality factors to precipitate psychological problems (Fisher, Murray, \& Frazer, 1985). Therefore, not surprisingly, international students who enter American universities and also must cope with cultural relocation tend to experience more psychological problems than do American students (Leong \& Chou, 1996; Mori, 2000; Pedersen, 1991; Sandhu \& Asrabadi, 1994). In addition, Yeh and Inose (2003) found that international students from Asian countries, including China, experience more acculturative stress than their counterparts from Europe.

Since the open-door policy in the 1980s, the number of mainland Chinese students attending Western universities has increased dramatically. In the 2004-2005 academic year, China became the second largest sending country, with 62,523 students enrolled in U.S. educational institutions (IIE, 2006). Because of the large cultural differences between long-isolated China and the Western world, Chinese students can face severe

Meirong Liu, M.A., is a Ph.D. candidate in the School of Social Work at the University of Illinois at Urbana-Champaign. The author would like to thank Dr. Mary K. Eamon, Associate Professor in the School of Social Work, University of Illinois at Urbana-Champaign, for her advice and encouragement regarding the development of this article. This article would not have been possible without her kind help.

Copyright (C) 2009 Advances in Social Work Vol. 10 No. 1 (Spring 2009), 69-86 
cultural shocks upon landing in the U.S. For example, embracing Confucian philosophy of harmony, which is passive and yielding (e.g., Oldstone-Moore, 2002), Chinese international students, in order to fulfill the expectations of American society and develop a non-confrontational relationship with members of the host society, may experience more difficulty than international students from other regions (Hsieh, 2006).

Research suggests that Chinese students' psychological problems should not be simply considered the same as those of Chinese immigrants. Berry, Kim, Minde, and Mok (1987) identified five distinct different acculturation groups on the basis of the nature of their contact with the host culture: immigrants, refugees, native people, ethnic groups, and sojourners. International students are most accurately described as sojourners according to this classification scheme (Wang \& Mallinckrodt, 2006). Their status as sojourners is more likely to contribute to difficulties such as lack of experience, social connectedness, and language ability. They are also less likely to have time to develop coping mechanisms to cope with discrimination and isolation and to establish a social support system, and may be more likely to be subject to many legal restrictions with regard to their academic eligibility and employment opportunities in the United States than immigrants (Bikos \& Furry, 1999). However, despite the unique issues faced by Chinese international students, little research has been done on this population.

This article addresses the mental health problems of Chinese international students who come from mainland China and attend American universities. The article first explores the students' views of mental health, followed by an examination of common sources of mental health problems experienced by them. The main intent of the article is to develop a nuanced understanding that is needed to develop culturally sensitive programs and services. The article concludes with programming suggestions to guide collaborative efforts between health providers, mental health social workers, faculty, and academic staff within universities for serving these international students more effectively. The ultimate goal is to help Chinese international students to enhance their functioning on university campuses.

\section{CONCEPTS OF MENTAL HEALTH IN CHINESE CULTURE}

\section{Introverted Concepts of Mental Health}

Chinese and American cultures are fundamentally different from each other. First, there are cultural variations in the concept of mental health. It has been suggested that Chinese culture has introverted inclinations, while modern Western culture has extroverted inclinations (Yip, 2005). Western concepts of mental health include role performance, adaptation, social functioning, and well-being in various aspects of social life (Laffrey, 1986). Individuals should function well in their families and employment settings. They also should improve or change oppressive social systems so as to assert their own rights and functions (Read \& Wallcraft, 1995).

In contrast, the introverted inclinations of Chinese culture imply self-absorption or self-demand, but not being demanding of others or trying to change the external environment (Yip, 2005). The traditional Confucian concepts of mental health, which still 
have a strong influence on Chinese people, suggest both internal and external requirements for individuals to maintain good mental health (Yip, 2005). The internal requirements encourage people to restrain emotions, including the expression of intense emotions and desires (Sue \& Sue, 1990). It suggests a step-by-step process to cultivate one's mind, restrain one's emotion, and discipline one's behavior so as to achieve peace of mind (Yip, 2005). The external requirements of Confucian concepts of mental health are moral standards in interpersonal and societal interactions. This suggests that one has to be kind, humane, and considerate in interactions with others; to be faithful to one's friends, family, and country; and to be forgiving of others' faults and shortcomings (Oldstone-Moore, 2002). In short, in Confucianism, internally, a mentally healthy individual is self-cultivated with a purified mind, a well-disciplined manner and mild expressions of emotion; externally, an individual is humane, righteous, faithful, and forgiving in interactions with others. Besides Confucianism, traditional Chinese medicine also describes that in order to maintain a good mental balance, one should reduce his or her inner desires, emotions, and stress to an extent that he or she is psychologically released from external and internal burdens. Finally, Taoism, another influential ideological concept in China, also points out that the best way to achieve a high level of mental health is to maintain a state of nothingness and let everything, including life and death and calamity and blessing, happen naturally (Yip, 1999).

These introverted traditional Chinese concepts of mental health, therefore, facilitate a form of passive egocentric preservation (Sue \& Sue, 1997). Chinese people are encouraged to restrain emotion and suppress individual rights to maintain harmony with other people and the law of nature. Under this influence, Chinese people typically choose self-control, self-discipline, and self-transcendence, rather than attempting to change the social environment. These tendencies may heavily influence the likelihood that individuals with problems will seek mental health services, as well as their responsiveness to services. For example, their introverted nature may help explain why Chinese international students tend to underuse mental health services, despite the fact that they experience more problems than students in general and have an urgent need for psychological assistance (Bradley et al., 1995; Pedersen, 1991). In addition, in the helping process, they are more likely than American students to terminate therapeutic relationships prematurely (Pedersen, 1991).

\section{Somatic Tendency: Integration of Body and Mind}

In Chinese culture and medicine, the body and mind are integrated (Kaptchuk, 2000); no distinction is made between physical and mental illness. Psychological, physical, and social factors are viewed as collectively contributing to the development of specific symptoms and illness (Lin \& Yi, 1997). Yet, people tend to manifest stress through physical symptoms. For example, "neurological weakness" is the preferred diagnosis over the psychological diagnosis of major depression, because it recognizes the presence of a physical process (Kleinman, 1986). Chinese international students, therefore, often seek medical help for their physical complaints, such as sleep disturbances, eating problems, fatigue, stomachache, or headache, even when those problems may stem from psychological stressors (Lin \& Yi, 1997). If such physical causes are not found, they 
probably will not continue to seek alternative causes or services that are mental health in nature.

The stigma of mental health illness, that is, losing face and embarrassment, may also prevent Chinese international students from seeking mental health services. These students may choose to keep their difficulties or emotional problems to themselves because they may imply personal failures, which actually only increases their vulnerability to depression (Heppner, et al., 2006). Empirical studies have found that although prevalent in all cultures, stigma of mental health illness is much more severe among Asians than among white Europeans and Americans (Fogel \& Ford, 2005; Furnham \& Chan, 2004).

\section{UNIQUE SOURCES OF MENTAL HEALTH PROBLEMS}

Understanding the sources of mental health problems among Chinese international students might facilitate counselors and educators in preventing or addressing these students' mental health problems. Chinese international students report a variety of mental health and personal concerns related to social interaction and communication problems, social connectedness, social support, filial piety, language barriers, homesickness, and academic, financial, and other difficulties (Leong \& Chou, 1996; Mallinckrodt \& Leong, 1992; Mori, 2000; Pedersen, 1991; Yeh \& Inose, 2002).

\section{Social Interaction and Communication Problems}

Asian students encounter values and customs in the U.S. that contradict those of their country of origin, such as cooperation versus competition (Lynch, 1992), collectivism versus individualism, and hierarchical relationships versus equality of relationships (Sue \& Sue, 1990). The accepted norms and behaviors in their country of origin may be ridiculed or misunderstood in the new environment, which can create confusion and discomfort (Lynch, 1992). Researchers suggest that Asian international students may have more difficulty than students from other regions in fitting the norms and expectations of the dominant culture (Hsieh, 2006). The students are aware of the need to learn Western values and cultural norms; however, despite the widespread belief that adolescents can adjust easily to a new culture (Huang, 1997; Hernandez \& McGoldrick, 1999), this learning process is not easy (James, 1997) and requires considerable time for many. This may explain why Chinese students who have been in the U.S. for a shorter time (one year or less) reported more stress than those who have been in the U.S. for a longer period of time (four years or more) (Wei et al., 2007). Overall, differences in cultural values and customs, especially when coupled with other factors such as language, often create social interaction, social connectedness, and social communication problems.

Cross-cultural differences in social interaction may prevent international students from forming close relationships with American students and may contribute to acculturative stress (Mallinckrodt \& Leong, 1992). For example, Yeh and Inose (2002) found that Asian immigrant students reported having social interaction problems. Lack of 
skill in English and strong cultural differences in interactional styles are among the factors argued to contribute to such problems.

The Chinese self is fundamentally a social one. Hsu (1953) has argued that people in the West are defined by their uniqueness and separateness from others. In contrast, people in the East are defined by their similarity and connection with others. The permeable boundary between the self and other is exemplified by the use of body parts to describe intimate relationships in the Chinese language. For example, siblings are referred to as "hand and foot" (Tung, 1994). As such, Chinese society has been characterized as interpersonally oriented and collectivistic (Markus \& Kitayama, 1991; Triandis, McCusker, \& Hui, 1990).

In contrast, there is a clear demarcation between the self and other in American mainstream culture, which highly values independence (Markus \& Kitayama, 1991). Americans are strong proponents of individual freedom and the right to exercise control over their lives without outside interference (Bellah, Madsen, Sullivan, Swidler, \& Tiption, 1985). Indeed, Hofstede (1980) found Americans scored significantly higher on individualism compared with Chinese people. For Americans, the wish for interpersonal connectedness is counterbalanced by a wish for autonomy and privacy (Lutz, 1985). As such, American society has been characterized as individualistic (Markus \& Kitayama, 1991; Triandis, McCusker \& Hui, 1990).

Hence, students from collectivistic cultural backgrounds may prioritize close relationships, and they may feel confused when interacting with Western students who tend to emphasize aspects of individualism, such as independence, assertiveness, and self-reliance (Cross, 1995). Consequently, many international students perceive friendships in western culture to be less permanent and lasting than in their home countries (Cross, 1995; Mori, 2000). Findings of a related study conducted in the United Kingdom suggest that Chinese international students often perceive the nature of relationships with host country students as problematic. Many felt "very alone" and "marginalized and isolated" from "home" students. They perceived that while "home" students are outwardly friendly, relationships usually remain superficial, and it is difficult to determine who is a friend (Bradley, 2000). In addition, Chinese international students can feel disappointed and discouraged with their interpersonal connections (Mori, 2000). These issues partially explain why international students tend to remain exclusively in limited groups of their fellow nationals (Yeh \& Inose, 2003). This is unfortunate, because close relationships with American students may predict better adjustment (Furnham \& Alibhai, 1985). Such isolation from American peers likewise forces international students into a highly artificial social environment dominated by "forced" interactions with a small number of their fellow nationals (Wright, 1987).

One study also indicates that Chinese international students are significantly more likely to have communication difficulties than Japanese and Korean international students (Yeh \& Inose, 2002). These greater difficulties are likely to result from the previously discussed unfamiliar values, behaviors, and norms. Furthermore, these difficulties can result in Chinese students becoming frustrated, irritated, depressed, and withdrawn. To complicate matters, it is difficult for these students to express their feelings due to 
linguistic barriers and the fact Chinese Confucian culture emphasizes self-control and deemphasizes emotional expression (Lee \& Zhan, 1998).

\section{Social Connectedness}

Social connectedness is defined as the self-in-relation-to-others, particularly the subjective recognition of being in a close relationship with the social world (Lee \& Robbins, 1995; 1998). This sense of connectedness guides individuals' feelings, thoughts, and behaviors in social situations (Lee \& Robbins, 1998). Thus, people with high levels of connectedness are better able to manage their own needs and emotions through cognitive processes (Tesser, 1991). On the other hand, people with low levels of connectedness are unable to effectively manage their needs and feelings and are more prone to low self-esteem, anxiety, and depression (Lee \& Robbins, 1998). International students with high social connectedness are, therefore, likely to adjust to the new social environment more easily and to experience less psychological stress than students with low social connectedness. Unfortunately, most Chinese international students stay in the circle of their national fellows, thus lack broader social connectedness (Yeh \& Inose, 2003). This formulation of cultural subgroups, in turn, tends to isolate international students even further (Hayes \& Lin, 1994).

\section{Social Support}

Research indicates that a loss of social support has a significant influence on the psychological well-being of international students (Hayes \& Lin, 1994; Mallinckrodt \& Leong, 1992; Pedersen, 1991). In moving to another country, international students tend to feel a deep sense of loss after leaving their families and friends (Hayes \& Lin, 1994). Establishing a comparable social support system in the U.S. also is extremely challenging for them (Mallinckrodt \& Leong, 1992). Therefore, international students may be suddenly deprived of social supports that validate their sense of self-esteem and provide emotional and social support (Mallinckrodt \& Leong, 1992; Pedersen, 1991; Sandhu, 1995). There is an old saying in China that captures this hardship: "everything is easy when you stay home, but everything becomes difficult when you are away from home.” Normal responses to the withdrawal of social support include anxiety, ranging from irritation and mild annoyance to the panic of extreme pain and the feelings of disorientation which accompany being lost (Pedersen, 1991).

Mallinckrodt and Leong (1992) investigated the significance of social support among international students and found that the quality of the social support system can have both a direct and a buffering effect when international students undergo psychological stress. These authors concluded that social support, especially from one's academic program, is essential to the welfare of international students. Differing cultural values with respect to how international students perceive social support systems and how satisfied they are with their social support networks also may influence their levels of acculturative stress (Yeh \& Inose, 2003).

Together, loss of social support and lack of social connectedness contribute to international students' acculturative stress. This acculturative stress often accompanies 
emotional pain, such as feelings of powerlessness, marginality, inferiority, loneliness, and perceived alienation and discrimination (Sandhu \& Asrabadi, 1998). In addition, particularly difficult acculturative stress experiences tend to remain within the individuals over a long period of time (Sanhu \& Asrabadi, 1998).

\section{Filial Piety}

In western culture, although parents are honored, there also is an emphasis on the nuclear family and independence, which reduces the importance of the family of origin. In fact, obligation to children is often stressed. However, as Hsu (1953) observed, what parents should do for their children is a priority for Americans; but for Chinese, what children should do for their parents is emphasized. In Chinese culture, persons are taught to obligate, respect, and have duty to their parents. The principles, which collectively are referred to as "Filial piety," are highly valued among Chinese people. Allegiance to parents is expected from offspring even after they have married and begun a family of their own and the pressure to meet parental obligations and expectations often clashes with individual goals and desires (Sue \& Sue, 1997). This latter observation is supported by research, which found nearly all of a sample of Chinese students seeking counseling (both foreign and America-born) experienced stress associated with filial piety (Bourne, 1975).

\section{Language Barriers}

Language barriers appear to be one of the most challenging issues for international students (Mori, 2000). In addition, Asian international students appear to have the greatest difficulty in the use of the English language among international students (AbuEin, 1993; Stafford, Marion, \& Salter, 1980). In Yeh and Inose's study (2003), higher frequency of use, fluency level, and the degree to which participants felt comfortable speaking English, predicted lower levels of acculturative distress among international students. This finding is associated with the fact that higher English fluency indicates smoother interactions with majority group members (Hayes \& Lin, 1994; Pedersen, 1991). Students with higher English fluency are able to more easily interact with people in new cultural settings, and this leads to greater feelings of adjustment. International students also may be less embarrassed and less self-conscious about their accent or ethnic background (Barratt \& Huba, 1994).

Higher levels of English language fluency also help international students perform at a higher level in some academic classes, because they may feel more comfortable in articulating their knowledge in classrooms and on essay exams or research papers (Kao \& Gansneder, 1995; Lin \& Yi, 1997). In contrast, low English language fluency is likely to affect international students' academic performance, which in turn negatively affects their psychological well-being (Lin \& Yi, 1997; Mori, 2000). Finally, international students with few English language skills might not be eligible for receiving teaching assistantships in universities because students complain about their foreign accents. In response, several state legislatures have passed laws mandating higher educational institutions to test foreign teaching assistants for English competency (Lin \& Yi, 1997) 


\section{Homesickness}

Another important stressor that international students face is homesickness. Previous research (Fisher \& Hood, 1987) demonstrates that homesickness often accompanies students' transition to university life. The previously mentioned strong links with family members in Chinese culture is likely to exacerbate this problem among Chinese international students.

In Lu's study (1990), every subject in the entire overseas Chinese student sample in Great Britain reported homesickness. Because there were no differences between the more homesick and less homesick groups in personality traits, or in perceived demands or symptoms, the study concluded that among Chinese international students, homesickness is a general widespread phenomenon resulting from being away from family.

\section{Academic Difficulties}

Chinese students also are likely to experience academic and career problems (Yeh \& Inose, 2003). There are several explanations for these negative outcomes. First, language difficulties and the difference in teaching styles between the U. S. and China can negatively influence Chinese students' academic performance, as they must learn entirely new classroom norms and skills (Yeh \& Inose, 2003). For example, the format and emphasis on classroom participation varies greatly between China and the U.S. In addition, since many Asian families strongly emphasize academic achievement (Homma-True, 1997; Kim, 1997; Sue \& Sue, 1997), Chinese international students likely feel pressured to succeed academically, even in the new environment. Moreover, those who are accepted by American universities, and particularly those who are provided scholarships, have always been excellent students (Pedersen, 1991). They would, of course, like to continue to be successful academically in the new environment.

Unfortunately, a strong emphasis on academic achievement can result in international students feeling too pressured to succeed. Sue and Sue (1990) noted that Asian students experience greater fear of academic failure than their non-Asian counterparts. In addition, academic achievement comes at a price. Sue and Zane (1985) found that foreign-born Chinese American university students achieve higher grade point averages by studying more hours per week. Partly because of this, the students experience greater anxiety, loneliness, and feelings of isolation and have difficulties in social interaction compared to other college students (Sue \& Morishima, 1982).

\section{Additional Factors Contributing to Mental Health Problems}

There are other factors which contribute to the psychological problems of Chinese international students. One study found that European international students are significantly less likely to experience acculturative distress than are students from the geographic regions of Asia, Africa, and Latin/Central America (Yeh \& Inose, 2003). The researchers believe that this is because European students experience less acculturative distress associated with racism and discrimination than students from these other regions (Yeh \& Inose, 2003). 
Maintaining non-immigrant status also creates barriers for Chinese international students. That is, they are legally prevented from assuming part-time student status or from temporarily dropping out, both of which often serve useful functions for domestic students. Otherwise, they would have to forfeit their student visas (Lin \& Yi, 1997). In addition, due to the strict immigrant visa policies, Chinese international students may experience difficulties in re-entering the U. S. if they need to leave for any reason. In particular, students who are majoring in certain "sensitive" technological subjects (e.g., chemical, biotechnology and biomedical engineering) are required to go through an often long "Visas Condor Program," in which the Consulate and the Department of State check the students' security background for counter-terrorism purposes (Jacobs, 2003). This, along with academic and financial issues, creates a major barrier for family reunions, which exacerbates the previously mentioned homesickness and loss of social support. Finally, financial problems could be severe for Chinese international students. The reasons include the considerable expense of U.S. study for foreign students and immigration regulations that strictly limit opportunities for employment outside the university and for welfare benefits, loans, and federal financial aid (Lin \& Yi, 1997; Pedersen, 1991).

\section{IMPLICATIONS}

The preceding discussion suggests several possibilities for addressing the mental health problems of Chinese international students. Implications are presented for health providers, mental health social workers, faculty, and academic staff within universities.

\section{Health Providers and Mental Health Social Workers}

It is important to educate health providers and mental health social workers on the importance of multicultural training to increase their awareness of the help seeking behaviors of Chinese international students. Because of cultural stigma or their lack of awareness of the availability of psychological services, Chinese international students may not seek formal assistance and may be reluctant to discuss personal problems (Pedersen, 1991). Thus, student service professionals can conduct culturally sensitive outreach programs to increase these students' awareness of the available resources to normalize their experiences (Wei et al., 2007). Counseling centers could also be located close to or in the same building as the health center or student affairs office to reduce the potential stigma that students may have when seeking help.

The somatization pattern among Chinese international students is important to monitor. College health and mental health care providers need to be aware that the tendency to manifest stress through physical symptoms may lead to an underutilization of potentially beneficial counseling and mental health services. Health providers should determine whether students are experiencing mental health problems while they are reporting physical problems, and refer such students to university or community mental health services (Mallinckrodt \& Leong, 1992).

Due to the unfamiliarity of Chinese students with mental health problems and services, preparing them for counseling by engaging in role preparation may be effective. 
Lambert and Lambert (1984) found that Asian clients who were told about what happens in therapy, the need for verbal disclosure, problems typically encountered by clients in therapy, the role of the therapist and client, misconceptions of therapy, and the need for attendance adjusted better to counseling than did a control group who did not receive role preparation. The clients who were prepared developed more accurate perceptions of the therapy and were more satisfied with their adjustment (Lambert \& Lambert, 1984).

Practitioners also might assist Chinese international students by teaching them effective coping skills. In a study on Chinese international students in Australia, two coping strategies were identified: problem-solving and seeking social support (Le \& Liu, 2007). In another study on Chinese immigrants' resettlement in Hong Kong, problemsolving and seeking social support were reported to be the most widely used coping strategies (Wong, 2002). To assist Chinese international students to use these strategies effectively, practitioners first must be aware of the common sources of the problems that the students may have (as was previously discussed in this article). Practitioners should focus on the specific problems identified by the students, and assess whether the identified problems have arisen from specific constraints such as language barriers. Second, assisting students in effectively solving problems and in enhancing social support requires practitioners to be aware of and provide information about the resources that may help solve problems and provide social support, For example, practitioners should be aware of available language training resources and make appropriate referrals when necessary (Wang \& Mallinckrodt, 2006). They must also be aware of the resources that may increase international students' contacts with local people or cultural events to establish social networks and to interact more with the host culture (Pan, Wong, Joubert, \& Chan, 2007). Third, it is equally important to help students recognize what they can and cannot resolve in a given time period, lest they become more emotionally upset or unhappy when nothing positive is forthcoming. While using these strategies, practitioners should also take the length of the time in the U.S. into consideration, as was discussed earlier. They may need to develop and implement different strategies for those who have studied and lived in the United States for a longer period of time as compared with those who recently arrived.

Berry et al. (1987) identified that integrated individuals, defined as those with a high degree of identification with both home and the host culture, tend to report lower levels of distress and better adjustment. Integration is achieved when one tries to maintain his or her own culture and also participates in the host culture. Thus, it appears that valuing both acculturation to the host culture and continuing strong identification with the home culture may be necessary for optimal socio-cultural adjustment. With this in mind, practitioners should not automatically set assimilation as the counseling goal when helping Chinese international students or other groups of international students with issues such as cultural adjustment. A more appropriate counseling goal might be to assist international students in developing cultural competence to function in the host culture while embracing their home culture. Such an approach might help them bridge and integrate the two cultures.

During the counseling process, practitioners should listen and talk to the students patiently. This allows the concerns of the students to be presented, and reduces the 
chance that the western world view of the therapist will be imposed on students (Ishisaka, Nguyen \& Okimoto, 1985; Lorenzo \& Adler, 1984; Tung, 1985). While engagement of clients in this respect is important in all counseling arrangements, the significant cultural differences and language problems discussed in this paper elevate the importance when working with Chinese international students.

Practitioners, however, should take an active and directive role in counseling sessions. Because of introverted Chinese cultural expectations and a lack of experience with mental health therapy, the clients will rely heavily on the counselor to furnish direction (Ishisaka et al., 1985; Lorenzo \& Adler, 1984;). Sue and Sue (1997) also found that in the process of psychotherapy, clients influenced by Chinese culture are more prone to external locus of control, that is, to being controlled by others.

\section{Universities}

Hsieh (2006) found that Chinese international students reported not receiving sufficient and immediate help from their institutions. Hsieh suggested that the large population of international students is usually disproportionate to the small number of staff in the international student office, and the office has difficulty offering quality services to meet the students' needs. Because most international students have problems with the English language and are unfamiliar with culture and the structure of higher education in the United States, they need much more help from their institutions than do American students. Therefore, to meet international students' needs, colleges and universities may need to recruit additional staff for their international student offices.

Social support, especially from one's academic program, is essential, and schools can play useful roles along these lines (Malinckrodt \& Leong, 1992). Interventions to assist Chinese international students in developing a strong social support system may be effective. For example, writing support letters for students or their family members in the visa application process can facilitate family reunions and reduce homesickness. Program advisors can play an active and important role in this process. Professors also should be informed of the potential psychological and culture issues of their students and should be aware of class diversity.

Providing students with mentors may be another useful approach. For example, Mallinckrodt and Leong (1992) found that quality relationships with faculty, as well as the quality of instruction perceived by students, can provide a strong protective function against the development of depression in international students undergoing stress. These findings are congruent with a number of other studies that underscore the importance of mentoring for U.S. graduate students (Cronan-Hillix, Gensheimer, Cronan-Hillix \& Davidson, 1986). The quality of student-faculty relationships may be especially important for international students, because of their preference for formal sources of help and their difficulty in building social relationships with American students (Furnham \& Bochner, 1982; Leong, 1984).

Pairing or mentoring international students with host national students could be a promising intervention (Bradley, 2000). This suggestion is based on previous research indicating that international students prefer host nationals to other nationals (Alexander, 
Klein, Workneh \& Miller, 1981). Host students can help international students by providing information and guidance on academics, social life, and western culture. Recruit more staff for the international student offices. Some of the participants reported that they could not receive sufficient and immediate help from their institutions.

Host family programs also have been successful (Pedersen, 1991). Such programs pair international students with local American families for monthly get-togethers to share activities, interests, and ideas. In these programs, international students can share time with a family, resulting in their feeling less lonesome for their own family. Together with peer help, these two programs can provide international students with social support and social connections. They also can help to improve language and provide more knowledge on western culture.

International programs of educational institutions can develop online communities for students and offer them ongoing support. Online ethnic groups appear to be an effective resource for providing social support and reducing acculturative stress for Chinese international students (Ye, 2006). The unique features of online groups, such as anonymity and easy accessibility, can encourage these students to express their feelings and exchange opinions and ideas and at the same time reduce stigma.

Parr, Bradley, and Bingi (1992) have made a number of other suggestions that can assist international students to successfully adjust to the U.S. For example, special efforts can be focused on helping students prepare for a letdown that often occurs in the second year of residence. Preparation might be enhanced by having their more senior international counterparts discuss successful methods for acquiring realistic expectations, coping with cultural differences, and being "school wise." In addition, given the great concern students have about their extended family, offices of student affairs could increase their efforts to promote family contact. Videos, letters informing parents of college activities, programs, departmental accomplishments or plans, special events, and services available to students could be sent more often to reassure parents that the college welcomes and values international students. Offices of student affairs might periodically feature articles in the school newspaper about international students, and these issues also could be mailed to parents. Dormitories and student service offices also could be encouraged to display pictures and celebrate some important Chinese festivals.

The suggestions discussed in this section, as well as a number of other creative efforts, can help prevent or reduce mental health problems of international Chinese students and assist them in making a successful social and academic adjustment. Acting on these suggestions also can convey the message that these students are cherished guests who enrich our university campuses.

\section{References}

Abu-Ein, M. M. (1995). A study of the adjustment problems of international students at Texas Southern University (Doctoral dissertation, Texas Southern University, 1993). Dissertation Abstracts International, 55(08), 2319A. 
Alexander, A. A., Klein, M. H., Workneh, F., \& Miller, M. H. (1981). Psychotherapy and the foreign student. In P. B. Pedersen, J. G. Draguns, W. J. Lonner, \& J. E. Trimble (Eds.), Counseling across cultures (pp. 227-243). Honolulu: East-West Center.

Barratt, M., \& Huba, M. E. (1994). Factors related to international undergraduate student adjustment in American community. College Student Journal, 28, 422-436.

Bellah, R. N., Madsen, R., Sullivan, W. M., Swidler, A., \& Tipton, S. M. (1985). Habits of the heart: Individualism and commitment in American life. Berkeley: University of California Press.

Berry, J. W., Kim, U., Minde, T., \& Mok, D. (1987). Comparative studies of acculturative stress. International Migration Review, 21, 490-511.

Bikos, L. H., \& Furry, T. S. (1999). The job search club for international students: An evaluation. The Career Development Quarterly, 48, 31-44.

Bourne, P. G. (1975). The Chinese student: Acculturation and mental illness. Psychiatry, 38, 269-277.

Bradley, G. (2000). Responding effectively to the mental health needs of international students. Higher Education, 39, 417-433.

Bradley, L., Parr, G., Lan, W.Y., Bingi, R., \& Gould, L. J. (1995). Counseling expectations of international students. International Journal for the Advancement of Counseling, 18, 21-31.

Cronan-Hillix, T., Gensheimer, L. K., Cronan-Hillix, W. A., \& Davidson, W. S. (1986). Students' views of mentors in psychology graduate training. Teaching of Psychology, 13, 123-127.

Cross, S. E. (1995). Self-construals, coping, and stress in cross-cultural adaptation. Journal of Cross-cultural Psychology, 26, 673-697.

Fisher, S., \& Hood, B. (1987). The stress of the transition to university: A longitudinal study of psychological disturbance and vulnerability to homesickness, British Journal of Psychology, 78, 425-442.

Fisher, S., Murray, K., \& Frazer, N. A. (1985). Homesickness, health and efficiency in first year students. Journal of Environmental Psychology, 5, 181-195.

Fogel, J., \& Ford, D. E. (2005). Stigma beliefs of Asian Americans with depression in an Internet sample. Canadian Journal of Psychiatry, 8, 470-477.

Furnham, A., \& Alibhai, N. (1985). The friendship networks of foreign students: A replication and extension of the function model. International Journal of Psychology, 20, 709-722.

Furnham, A., \& Bochner, S. (1982). Social difficulty in a foreign culture: An empirical analysis of culture shock. In S. Bochner (Ed.), Cultures in contact: Studies in crosscultural interactions (pp. 161-198). New York: Pergamon. 
Furnham, A., \& Chan, E. (2004). Lay theories of schizophrenia: A cross-cultural comparison of British and Hong Kong Chinese attitudes, attributions and beliefs. Social Psychiatry and Psychiatric Epidemiology, 39, 543-552.

Hayes, R. L., \& Lin, H. R. (1994). Coming to America: Developing social support systems for international students. Journal of Multicultural Counseling and Development, 22, 7-16.

Heppner, P. P., Heppner, M. J., Lee, D. G., Wang, Y.-W., Park, H.-J., \&Wang, L.F. (2006). Development and validation of a collectivistic coping styles inventory. Journal of Counseling Psychology, 53, 107- 125.

Hernandez, M., \& McGoldrick, M. (1999). Migration and the family life cycle. In B. Carter \& M. McGoldrick (Eds.), The expanded family life cycle: Individual, family and social perspectives ( $3^{\text {rd }}$ ed., pp. 169-173). Boston, MA: Allyn \& Bacon.

Hofstede, G. (1980). Culture's consequences: International differences in work-related values. Beverly Hills, CA: Sage,

Homma-True, R. (1997). Japanese American families. In E. Lee (Ed.), Working with Asian Americans: A guide for clinicians (pp. 114-124). New York: Guilford Press.

Hsieh, M. (2006). Identity negotiation among female Chinese international students in second-language higher education. College Student Journal, 40(4), 870-884.

Hsu, F. L. K. (1953). Americans and Chinese: Two ways of life. New York: Abelard Schuman.

Huang, L. N. (1997). Asian American adolescents. In E. Lee (Ed.), Working with Asian Americans: A guide for clinicians (pp. 175-195). New York: Guilford Press.

Institute of International Education. (2006). Open doors 2005: International students in the United States. Retrieved May 25, 2007 from http://opendoors.iienetwork.org/?p=69736.

Ishisaka, H. A., Nguyen, Q. T., \& Okimoto, J. T. (1985). The role in the mental health treatment of Indochinese refugees. In T.C. Owan (Ed.), Southeast Asian mental health treatment, prevention services, training, and research. Washington, DC: National Institute of Mental Health.

Jacobs, J. L. (2003). Foreign students and scholars in the age of terrorism. Retrieved September 12, 2007 from http://travel.state.gov/law/legal/testimony/testimony_797.html.

James, D. C. S. (1997). Coping with a new society: the unique psychosocial problems of immigrant youth. Journal of School Health, 67, 98-102.

Kaptchuk, T. J. (2000). The web that has no weaver: Understanding Chinese medicine ( $2^{\text {nd }}$ ed.). Lincolnwood, IL: Contemporary Books. 
Kao, C.-W., \& Gansneder, B. (1995). An assessment of class participation by international graduate students. Journal of College Student Development, 36, 132140.

Kim, S. C. (1997). Korean American families. In E. Lee (Ed.), Working with Asian Americans: A guide for clinicians (pp. 125-135). New York: Guilford Press.

Kleinman, A. (1986). Social origins of distress and disease: Depression, neurasthenia, and pain in modern China. New Haven, CT: Yale University Press.

Laffrey, S. C. (1986). Development of a health conception scale. Research in Nursing and Health, 9, 107-113.

Lambert, R. G., \& Lambert, M. J. (1984). The effects of role participation for psychotherapy on immigrant clients seeking mental health services in Hawaii. Journal of Community Psychology, 12, 263-275.

Le, T., \& Liu, L. (2007). Acculturation and coping strategies: Chinese students experiences in an Australian tertiary education discourse. Presentation at the $5^{\text {th }}$ International Conference on ELT in China \& the $1^{\text {st }}$ Congress of Chinese Applied Linguistics. Retrieved from http://www.celea.org.cn/2007/attachment/5-76-1.ppt.

Lee, L. C., \& Zhan, G. (1998). Psychosocial status of children and youths. In L. C. Lee \& N. W. S. Zane (Eds.), Handbook of Asian American Psychology (pp.137-163). Thousand Oaks, CA: Sage.

Lee, R. M., \& Robbins, S. B. (1995). Measuring belongingness: The social connectedness and the social assurance scales. Journal of Counseling Psychology, 42, 232-241.

Lee, R. M., \& Robbins, S. B. (1998). The relationship between social connectedness and anxiety, self-esteem, and social identity. Journal of Counseling Psychology, 45, 338345 .

Leong, F. T. L. (1984). Counseling international students: Searchlight plus \#56. Ann Arbor, MI: University of Michigan, ERIC Counseling and Personnel Services Clearinghouse.

Leong, F. T. L., \& Chou, E. L. (1996). Counseling international students. In P. B. Pedersen, J. G. Draguns, W. J. Lonner, \& J. T. Trimble (Eds.), Counseling across cultures (pp. 210-242). Thousand Oaks, CA: Sage.

Lin, J. C. G., \& Yi, J. K. (1997) Asian international students’ adjustment: Issues and program suggestions. College Student Journal, 31, 473-479.

Lorenzo, K. K., \& Adler, D. A. (1984). Mental health services for Chinese in a community health center. Social Casework, 65, 600-610.

Lu, L. (1990). Adaptation to British universities: Homesickness and mental health of Chinese students. Counseling Psychology Quarterly, 3, 225-233. 
Lutz, C. (1985). Depression and the translation of emotional worlds. In A. Kleinman \& B. Good (Eds.), Culture and depression (pp. 63-100). Berkeley: University of California Press.

Lynch, E. W. (1992). From culture shock to cultural learning. In E. W. Lynch \& M. J. Hanson (Eds.), Developing cross-cultural competence: A guide for working with young children and their families (pp. 19-34). Baltimore, MD: Paul H. Brookes Publishing.

Mallinckrodt, B., \& Leong, F. T. L. (1992). International graduate students, stress, and social support. Journal of College Student Development, 33, 71-78.

Markus, H., \& Kitayama, S. (1991). Culture and self: Implications for cognition, emotion, and motivation. Psychological Review, 98, 224-253.

Mori, S. (2000). Addressing the mental health concerns of international students. Journal of Counseling and Development. 78, 137-144.

Oldstone-Moore, J. (2002). Confucianism. New York: Oxford University Press.

Pan, J. Y., Wong, D., Joubert, L., \& Chan, C. (2007). Acculturative stressor and meaning of life as predictors of negative affect in acculturation: a cross-cultural comparative study between Chinese international students in Australia and Hong Kong. Australian and New Zealand Journal of Psychiatry, 41, 740-750.

Parr, G., Bradley, L., \& Bingi, R. (1992). Concerns and feelings of international students. Journal of College Student Development, 33, 20-25.

Pedersen, P. B. (1991). Counseling international students. The Counseling Psychologist, $19,10-58$.

Read, J., \& Wallcraft, J. (1995). Guidelines in equal opportunities and mental health. London: MIND Publications.

Sandhu, D. S. (1995). An examination of the psychological needs of the international students: Implications for counseling and psychotherapy. International Journal for the Advancement of Counseling, 17, 229-239.

Sandhu, D. S., \& Asrabadi, B. R. (1994). Development of an acculturative stress scale for international students: Primary findings. Psychological Reports, 75, 435-448.

Sodowsky, G. R., Maguire, K., Johnson, P., Ngumba, W., \& Kohles, R. (1994). World views of White American, mainland Chinese, Taiwanese, and African students: An investigation into between-group differences. Journal of Cross-Cultural Psychology, 25, 309-324.

Stafford, T. H., Jr., Marion, P. B., \& Salter, M. L. (1980). Adjustment of international students. NASPA Journal 18(1), 40-45.

Sue, D., \& Sue, D. W. (1997). Counseling Strategies for Chinese Americans, in C. C. Lee (Ed.), Multicultural issues in counseling: New approaches to diversity (pp. 79-90). Alexandria, VA: American Counseling Association. 
Sue, D. W., \& Morishima, J. K. (1982). The mental health of Asian Americans. San Francisco. CA: Jossey-Bass Publishers.

Sue, D. W., \& Sue, D. (1990). Counseling the culturally different: Theory and practice $\left(2^{\text {nd }}\right.$ ed. $)$. New York: Wiley.

Sue, S., \& Zane, N. W. S (1985). Academic achievement and socio-emotional adjustment among Chinese university students. Journal of Counseling Psychology, 32, 570-590.

Tesser, A. (1991). Social versus clinical approaches to self psychology: The selfevaluation maintenance model and Kohutian object relations theory. In R. C. Curtis (Ed.), The relational self: Theoretical convergences in psychoanalysis and social psychology (pp. 257-281). New York: Guilford Press.

Triandis, H. C., McCusker, C., \& Hui, C. H. (1990). Multimethod probes of individualism and collectivism. Journal of Personality and Social Psychology, 59, 79-86.

Tung, T. M. (1985). Psychiatric care for Southeast Asian: How different is different? In T.C. Owan (Ed.), Southeast Asian mental health, treatment, prevention services, training, and research. Washington, DC: National Institute of Mental Health.

Tung, T. M. (1994). Symbolic meanings of the body in Chinese culture and "somatization”. Culture, Medicine and Psychiatry, 18, 483-492.

Wang, C. \& Mallinckrodt, B. (2006). Acculturation, attachment, and psychosocial adjustment of Chinese/Taiwanese international students. Journal of Counseling Psychology, 503(4), 422-433.

Wei, M., Heppner, P. P., Mallen, M., Ku, T.-Y., Liao, K. Y.-H., \& Wu, T. F. (2007). Acculturative stress, perfectionism, years in United States, and depression among Chinese international students. Journal of Counseling Psychology, 54, 385-394.

Wong, D. (2002). Stage-specific and culture-specific coping strategies used by mainland Chinese immigrants during resettlement in Hong Kong: A qualitative analysis. Social Work in Health Care, 35, 479-499.

Wright, D. J. (1987). Minority students: Developmental beginnings. New Directions for Student Services, 38, 5-21.

Ye, J. (2006). An examination of acculturative stress, interpersonal social support, and use of online ethnic social Groups among Chinese international students. The Howard Journal of Communications, 17, 1-20.

Yeh, C., \& Inose, M. (2002). Difficulties and coping strategies of Chinese, Japanese, and Korean immigrant students. Adolescence, 37, 69-82.

Yeh, C., \& Inose, M. (2003). International students' reported English fluency, social support satisfaction, and social connectedness as predictors of acculturative stress. Counseling Psychology Quarterly. 16, 15-28. 
Yip, K. S. (1999). Traditional Chinese Confucian, Taoistic and medical mental health concepts in pre-Chin-period. Asian Journal of Counseling, 6, 35-55.

Yip, K. S. (2005). Chinese concepts of mental health: Cultural implications for social work practice. International Social Work, 48, 391-407.

\section{Author's note:}

Address correspondence to: Meirong Liu, M.A., Doctoral Candidate, School of Social Work, University of Illinois at Urbana-Champaign, 1010 W. Nevada, Urbana, IL 61801. Email: mliu22@uiuc.edu. 